\title{
Synthesis of Star-Shaped $\varepsilon$-Caprolactone Oligomers for use as Plasticizers of Poly(L-Lactide) Bioplastic Films
}

\section{THANONCHAT IMSOMBUT, MANGKORN SRISA-ARD AND YODTHONG BAIMARK*}

\author{
Biodegradable Polymers Research Unit, Department of Chemistry and Center of Excellence for \\ Innovation in Chemistry, Faculty of Science, Mahasarakham University, \\ Mahasarakham 44150, Thailand. \\ ${ }^{*}$ Corresponding author E-mail: yodthong.b @ msu.ac.th
}

http://dx.doi.org/10.13005/ojc/330213

(Received: November 28, 2016; Accepted: February 24, 2017)

\begin{abstract}
Liquid star-shaped e-caprolactone (CL) oligomers were synthesized by ring-opening reaction of $\mathrm{CL}$ using a six terminal hydroxyl group initiator, Boltorn ${ }^{\circledR} \mathrm{H} 2004$, for use as new plasticizers of poly(L-lactide) (PLA) films. The Boltorn-CL oligomers containing two and four units of CL on each oligomer arm were prepared. The PLA/oligomer blend films were prepared by solution blending before film casting. A phase separation led to the formation of plasticizer droplets. The CL arms reduced the phase separation. The plasticizer blending decreased slightly the $T_{g}, T_{c}$ and $T_{m}$ of the PLA films. The crystallinities of the PLA films increased with the Boltorn-CL blend ratio but they did not with the Boltorn ${ }^{\circledR}$ H2004. The Boltorn-CL blending improvedflexibility of the PLA films, but Boltorn ${ }^{\circ} \mathrm{H} 2004$ blending did not. The increasing of CL units decreased the flexibility of the PLA films. The Boltorn-CL oligomers could be used as plasticizers for PLA films.
\end{abstract}

Keywords: Poly(L-lactide),Boltorn-CL, Oligomer, Plasticizer, Mechanical properties

\section{INTRODUCTION}

Poly(L-lactide) (PLA), one of the most important bioplastics, has attracted increasing attention as a candidate for use in many application fields, such as tissue scaffold, drug delivery systems, packaging films and so on, because of its renewability, biodegradability, biocompatibility, good processability and good mechanical properties. ${ }^{1-4}$ However, the low elongation at break and the high modulus of the PLA films have limited applications in packaging situations.

The flexibility of PLA films can be improved either by copolymerization ${ }^{5,6}$ or by plasticizer blending. ${ }^{7}$ The plasticizer blending is more convenient, more efficient, lower cost and faster compared to copolymerization. Low molecular weight plasticizers, such as citrate esters, significantly reduce the $T_{g}$ and obviously improve the elongation at break of the PLA 
films. ${ }^{8,9}$ However, the migration of these plasticizers from the PLA film matrix to the film surface due to their high mobility increases the $T_{g}$ and reduces the film drawability with aging, which is the main problem. ${ }^{6,10}$ High molecular weight plasticizers, such as poly(ethylene glycol) (PEG) and poly(propylene glycol) (PPG), were then investigated for plasticizing of PLA films to decrease the migration of plasticizers on aging. ${ }^{11-14}$ However, the high molecular weight plasticizers usually induce phase separation in the PLA film matrices. It has been reported that tiny pools of liquid plasticizers, such as PPGs, are dispersed in the PLA film matrices and may locally plasticize PLA during plastic flow and have better effects on drawability than the crystallizable plasticizers such as PEGs. ${ }^{13,14}$ The PPGs have also been shown to give efficient plasticization to improve the flexibility of the PLLA.

Semi-crystalline poly(e-caprolactone) (PCL) is a flexible biodegradable polyester due to its very low $\mathrm{T}_{\mathrm{g}}$ (around $-60^{\circ} \mathrm{C}$ ). The five methylene units of the CL units induce high chain mobility and low $\mathrm{T}_{\mathrm{g}}$. PCL and CL oligomers have been investigated as biodegradable plasticizers. ${ }^{15-17}$ However, to the best of our knowledge, the plasticization effect of starshaped CL oligomers on PLA films has not been reported so far.

Thus, this paper describes the synthesis of liquid $\mathrm{CL}$ oligomers with 6-arm star-shaped structures for plasticizing PLA film. Effects of the CL chain length (two and four units) on each arm and plasticizer blend ratios $(5-20 \mathrm{wt} \%$ ) on the phase separation, thermal properties and mechanical properties of the PLA blend films were evaluated. The PLA films blended with the 6-arm initiator, Boltorn ${ }^{\circledR}$ $\mathrm{H} 2004$, were also prepared for comparison.

\section{EXPERIMENTAL SECTION}

\section{Materials}

The poly(L-lactic acid) (PLA) was synthesized in our research unit at Mahasarakham University by ring-opening polymerization of a L-lactide monomer in bulk at $165^{\circ} \mathrm{C}$ for $2.5 \mathrm{~h}$. under a nitrogen atmosphere using $0.01 \mathrm{~mol} \%$ stannous octoate (95\%, Sigma) and $0.14 \mathrm{~mol} \% 1$-dodecanol (98\%, Fluka) as the initiating system. The obtained
PLA was granulated before drying in a vacuum at $110{ }^{\circ} \mathrm{C}$ for $2 \mathrm{~h}$ to remove any un-reacted lactide. The intrinsic viscosity $([\eta])$ and viscosity-average molecular weight $\left(M_{v}\right)$ of the PLA were determined in chloroform at $25^{\circ} \mathrm{C}$, and they were $2.53 \mathrm{dL} / \mathrm{g}$ and $104,700 \mathrm{~g} / \mathrm{mol}$, respectively. The e-caprolactone (CL, 99\%, Acros Organics) monomer was purified by distillation under reduced pressure before use. A liquid fatty acid modified dendritic polyol with six terminal hydroxyl groups, trade name Boltorn $₫$ $\mathrm{H} 2004$, with a molecular weight of $3,100 \mathrm{~g} / \mathrm{mol}$ (Perstrop) was used without further purification. All reagents used were analytical grade.

\section{Synthesis of CL oligomers}

The CL oligomers were synthesized by ring-opening polymerization of the $\mathrm{CL}$ monomer in bulk at $145^{\circ} \mathrm{C}$ for $24 \mathrm{~h}$ under a nitrogen atmosphere using 0.04 mol\% stannous octoate and Boltorn ${ }^{\circledR}$ $\mathrm{H} 2004$ as the initiating system, as shown in Scheme 1. The resulting oligomers were purified by heating at $110^{\circ} \mathrm{C}$ under a vacuum for $6 \mathrm{~h}$ to remove un-reacted $\mathrm{CL}$ monomer. The CL monomers with two and four units were reacted at the hydroxyl end-groups of the Boltorn' ${ }^{\circ} 2004$, giving Boltorn-2CL and Boltorn-4CL, respectively.

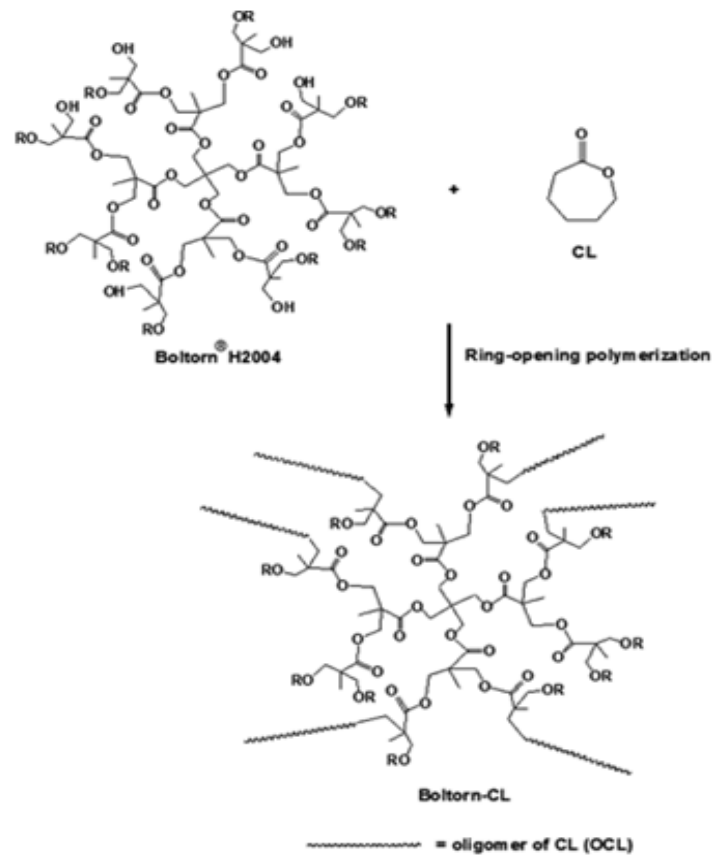

Scheme 1: Reaction of Boltorn-CL formation. 


\section{Characterization of CL oligomers}

The molecular weight characteristics, including number-average molecular weight $\left(M_{n}\right)$ and molecular weight distribution (MWD), of the CL oligomers were determined by Gel Permeation Chromatography (GPC) using a Waters e2695 separation module equipped with PLgel $10 \mu \mathrm{m}$ mixed B 2 columns operating at $40^{\circ} \mathrm{C}$ at a flow rate of 1.0 $\mathrm{mL} / \mathrm{min}$ and employing a refractive index detector. Tetrahydrofuran was used as the solvent.

The chemical structures of the CL oligomers were investigated by ${ }^{1} \mathrm{H}-\mathrm{NMR}$ spectrometry using a Varian Mercury Plus $400 \mathrm{MHz}{ }^{1} \mathrm{H}-\mathrm{NMR}$ spectrometer at $25^{\circ} \mathrm{C}$ with $\mathrm{CDCl}_{3}$ as the solvent. Tetrametylsilane was used as the internal reference.

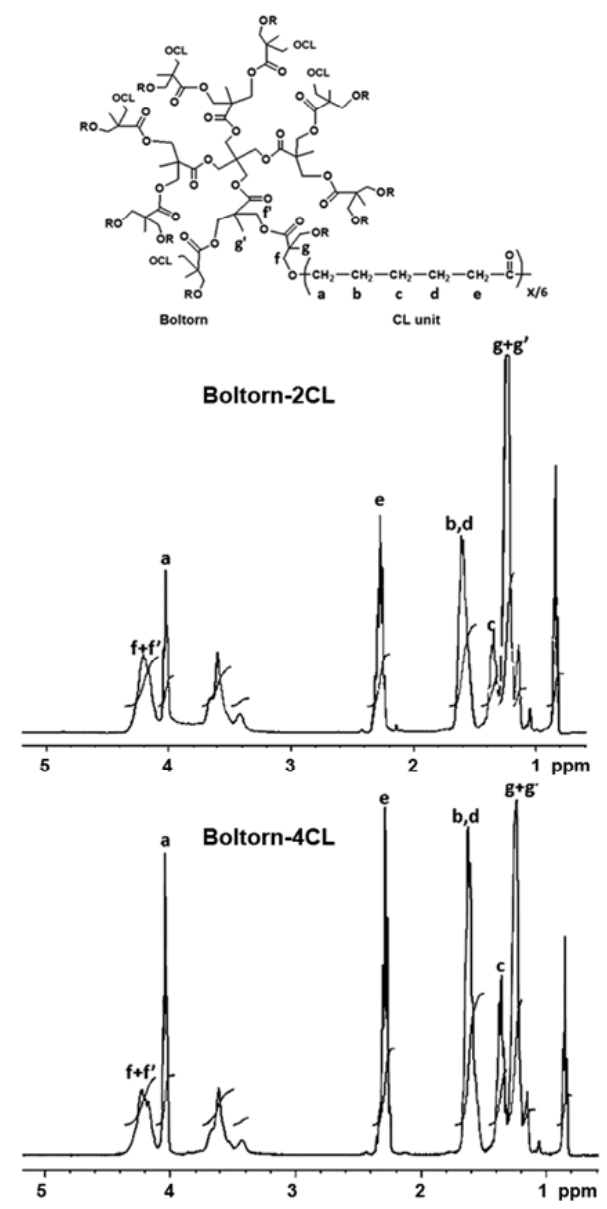

Fig. 1: ${ }^{1} \mathrm{H}-\mathrm{NMR}$ spectra of (above) Boltorn-2CL and (below) Boltorn-4CL in $\mathrm{CDCl}_{3}$ (peak assigments as shown).
The thermal transition properties of the $\mathrm{CL}$ oligomerswere determined by Differential Scanning Calorimetry (DSC) under a nitrogen flow using a Perkin-Elmer Pyris Diamond DSC to detect the glass transition temperature $\left(T_{g}\right)$ and melting temperature $\left(T_{m}\right)$. For DSC, samples (3-5 mg) were heated at $10^{\circ} \mathrm{C} / \mathrm{min}$ over a temperature range of 0 to $200{ }^{\circ} \mathrm{C}$ for the $1^{\text {st }}$ heating scan. Then, the samples were quenched to $0{ }^{\circ} \mathrm{C}$ according to the DSC instrument's own default cooling mode before heating from 0 to $200{ }^{\circ} \mathrm{C}$ for the $2^{\text {nd }}$ heating scan. The $\mathrm{T}_{\mathrm{g}}$ was taken as the midpoint of the heat capacity increment associated with the glass-to-rubber transition. The $T_{m}$ was measured as the peak value of the endothermal phenomena in the DSC curve.

The thermal stability (or thermal decomposition) of the CL oligomers was determined by thermogravimetric analysis (TGA) in a nonisothermal mode using aTA-Instrument SDT Q600 TGA. For the TGA analysis, samples of $5-10$ $\mathrm{mg}$ were heated at $20^{\circ} \mathrm{C} / \mathrm{min}$. under a nitrogen atmosphere over the temperature range of 50 to $800^{\circ} \mathrm{C}$. The TG thermogram was obtained as a weight loss profile. The temperature of the maximum decomposition rate $\left(T_{d, \max }\right)$ was derived from a derivative TG (DTG) thermogram.

\section{Preparation of PLA/oligomer blend films}

The PLA/oligomer blend films were prepared by solution blending before film casting. Chloroform was used as a blending solvent. The blend solution $(0.4 \mathrm{~g} / 20 \mathrm{ml})$ was poured on to a glass petri dish and evaporated at $40{ }^{\circ} \mathrm{C}$ for $24 \mathrm{~h}$ before drying in a vacuum at $70^{\circ} \mathrm{C}$ for $24 \mathrm{~h}$. The PLA blend films with PLA/oligomer blend ratios of $95 / 5$, $90 / 10$ and $80 / 20 \%$ wt were investigated. The neat PLA and PLA/Boltorn ${ }^{\circledR} \mathrm{H} 2004$ blend films were also prepared by the same method for comparison. The film thicknesses were approximate $50 \mu \mathrm{m}$.

\section{Characterization of PLA/oligomer blend films}

The morphology of the blend films was determined by scanning electron microscopy (SEM) using a JEOL JSM-6460LV SEM. The film samples were coated with gold to enhance conductivity before scanning.

The thermal transition properties of the blend films were investigated by the DSC method as 
described above to observe the $T_{g}, T_{m}$, crystallizing temperature $\left(T_{c}\right)$, heat of crystallization $\left(\Delta \mathrm{H}_{c}\right)$ and heat of melting $\left(\Delta \mathrm{H}_{\mathrm{m}}\right)$. The $\mathrm{T}_{\mathrm{c}}$ was measured as the peak value of the exothermal phenomena in the DSC curve. The $\Delta \mathrm{H}_{\mathrm{c}}$ and $\Delta \mathrm{H}_{\mathrm{m}}$ were calculated from the total areas of the $T_{c}$ and $T_{m}$ peaks, respectively. The degree of crystallinity $\left(X_{c}\right)$ of the PLA phase was calculated from equation (1).

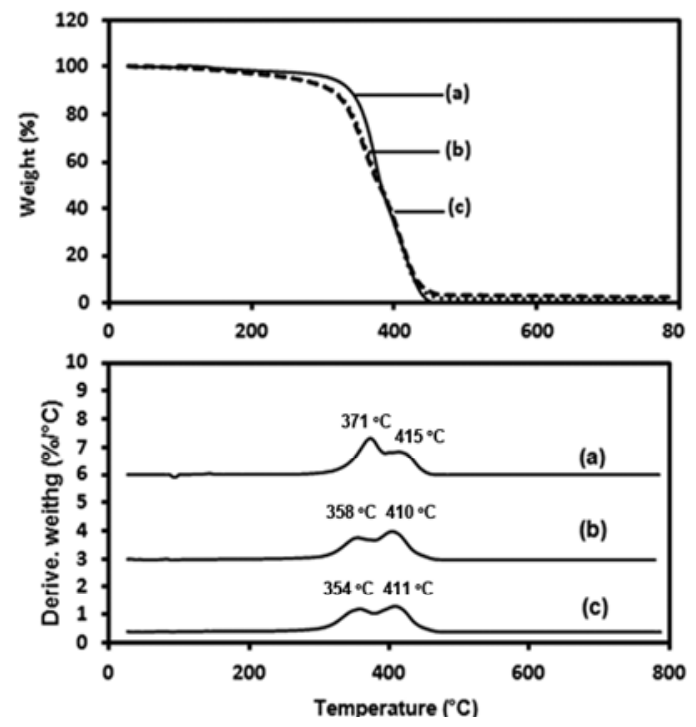

Fig. 2: TG (above) and DTG (below) thermograms of (a) Boltorn H2004, (b) Boltorn-2CL and (c) Boltorn-4CL.
$X_{c}(\%)=\left[\left(\Delta \mathrm{H}_{\mathrm{m}}-\Delta \mathrm{H}_{\mathrm{c}}\right) /\left(\mathrm{w}_{\mathrm{PLA}} \Delta \mathrm{H}_{\mathrm{m}, 100 \%}\right)\right] \times 100 \%$

where $w_{P L A}$ is the weight fraction of PLA in the blend films. $\Delta \mathrm{H}_{\mathrm{m}}$ and $\Delta \mathrm{H}_{\mathrm{c}}$ are the heat of melting and heat of crystallization, respectively, thatwere obtained from the DSC method. The heat of melting for $100 \%$ crystallinity $\left(\Delta \mathrm{H}_{\mathrm{m}, 100 \%}\right)$ of PLA is 93.7 $\mathrm{J} / \mathrm{g} \cdot{ }^{18-20}$

The mechanical properties, including stress at break, elongation at break and initial Young's modulus, of the blend films were determined at $25^{\circ} \mathrm{C}$ and $65 \%$ relative humidity with a Lloyds LRX+ Universal Mechanical Testing Machine. The film samples $(80 \times 10 \mathrm{~mm})$ were tested with a gauge length of $25 \mathrm{~mm}$ and a crosshead speed of $10 \mathrm{~mm} /$ $\mathrm{min}$. The mechanical properties were averaged from five measurements for each sample.

\section{RESULTS and DISCUSSIONS}

\section{Characterization of CL oligomers}

The yields of the CL oligomers measured by the evaporation of un-reacted $\mathrm{CL}$ were higher than $90 \%$. Both the Boltorn-2CL and the Boltorn$4 \mathrm{CL}$ were liquid at room temperature, similar to the initiator, Boltorn ${ }^{\circledR} \mathrm{H} 2004$. The $\mathrm{M}_{n}$ and MWD of the Boltorn $\mathrm{H} 2004$ obtained from GPC were 2,600 $\mathrm{g} / \mathrm{mol}$ and 1.5 , respectively. The GPC curves of

Table 1: Thermal transition properties of neat PLA and PLA blend films from the $2^{\text {nd }}$ heating scan DSC thermograms

\begin{tabular}{lcccc}
\hline PLA/plasticizer ratio (w/w) & $\mathbf{T}_{\mathrm{g}}\left({ }^{\circ} \mathbf{C}\right)$ & $\mathbf{T}_{\mathrm{c}}\left({ }^{\circ} \mathbf{C}\right)$ & $\mathbf{T}_{\mathrm{m}}\left({ }^{\circ} \mathbf{C}\right)$ & $\boldsymbol{X}_{c}(\%)$ \\
\hline Neat PLA film & 55 & 100 & 175 & 28.6 \\
PLA/Boltorn blend films & & & & \\
$95 / 5$ & 51 & 98 & 174 & 27.6 \\
$90 / 10$ & 50 & 97 & 174 & 26.6 \\
$80 / 20$ & 47 & 94 & 173 & 21.2 \\
PLA/Boltorn-2CL blend films & & & & \\
$95 / 5$ & 51 & 99 & 174 & 19.3 \\
$90 / 10$ & 50 & 98 & 173 & 23.5 \\
$80 / 20$ & 49 & 95 & 173 & 42.9 \\
PLA/Boltorn-4CL blend films & & & & \\
$95 / 5$ & 53 & 99 & 173 & 17.6 \\
$90 / 10$ & 49 & 97 & 173 & 23.9 \\
$80 / 20$ & 48 & 94 & 172 & 49.8 \\
\hline
\end{tabular}


both the Boltorn-2CL and the Boltorn-4CL were of the unimodal type with the MWDs being 1.6 and 1.8 , respectively. The $M_{n} s$ of the $C L$ oligomers from the GPC method were higher than the Boltorn ${ }^{\circledR}$ $\mathrm{H} 2004$ and increased with the $C L$ units. The $M_{n} s$ of the Boltorn-2CL and the Boltorn-4CL were 3,000 and $3,500 \mathrm{~g} / \mathrm{mol}$, respectively. The GPC results indicated that the $\mathrm{CL}$ monomers were connected to the Boltorn ${ } \mathrm{H} 2004$ molecules. CL oligomers with different $C L$ chain lengths can be prepared.
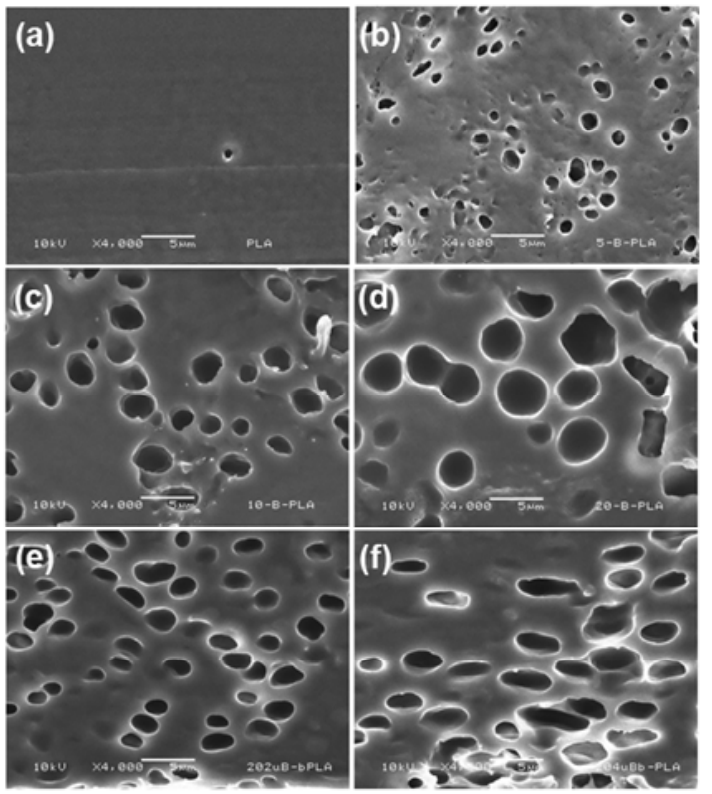

Fig. 3: SEM images of fractured surfaces of (a) neat PLA, (b) 95/5 PLA/Boltorn, (c) 90/10 PLA/ Boltorn, (d) 80/20 PLA/Boltorn, (e) 80/20 PLA/ Boltorn-2CL and (f) $80 / 20$

PLA/Boltorn-4CL blend films (all bars $=5 \mathrm{~mm}$ ).

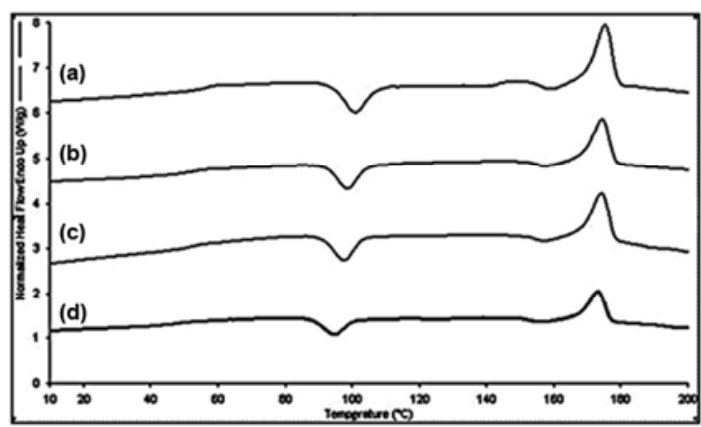

Fig. 4: DSC thermograms of (a) neat PLA, (b) 95/5 PLA/Boltorn, (c) 90/10 PLA/Boltorn and (d) $80 / 20$ PLA/Boltorn blend films.
The chemical structures of the $\mathrm{CL}$ oligomers were determined from ${ }^{1} \mathrm{H}-\mathrm{NMR}$. Figure 1 shows the ${ }^{1} \mathrm{H}-\mathrm{NMR}$ spectra of the $\mathrm{CL}$ oligomers including the peak assignments. The peaks of $\mathrm{a}-\mathrm{e}$ were assigned to the methylene protons $\left(-\mathrm{CH}_{2}{ }^{-}\right)$of the $\mathrm{CL}$ units. ${ }^{21}$ The peaks of $f$ and $g$ were assigned to the methylene $\left(-\mathrm{CH}_{2}-\right)$ and methyl $\left(-\mathrm{CH}_{3}\right)$ protons at the outer structure of the Boltorn units, respectively. ${ }^{22}$ Meanwhile the peaks of f' and g' were assigned to the methylene $\left(-\mathrm{CH}_{2}-\right)$ and methyl $\left(-\mathrm{CH}_{3}\right)$ protons at the inner structure of the Boltorn units, respectively. ${ }^{22}$ The ${ }^{1} \mathrm{H}-\mathrm{NMR}$ results confirm that the Boltorn-CL oligomers consisted of both the Boltorn and the $\mathrm{CL}$ characters. It should be noted that the peak area ratio of the CL/Boltorn units such as area ratio of peak a/peak $f+f$ ', increased as the $C L$ units increased from two to four units in each arm. The ${ }^{1} \mathrm{H}-\mathrm{NMR}$ results support that the $C L$ units increased with the initial $C L$ feed ratio.

From the DSC analysis (DSC thermograms not shown), both the $1^{\text {st }}$ and the $2^{\text {nd }}$ heating scans did not exhibit the $T_{m}$ of the $C L$ crystalline. The $C L$ sequences with two and four units of the Boltorn$2 \mathrm{CL}$ and the Boltorn-4CL, respectively, could not be crystallized. They are liquid at room temperature.

Figure 2 shows the thermogravimertic (TG) and derivative TG (DTG) thermograms of the Boltorn' ${ }^{\circ} \mathrm{H} 2004$ and the $\mathrm{CL}$ oligomers from the

Table 2: $T_{d, \max }$ values of neat PLA and PLA blend films from DTG thermograms

\begin{tabular}{lc}
\hline PLA/plasticizer blend ratio (w/w) & $\mathbf{T}_{\mathrm{d}, \max }\left({ }^{\circ} \mathbf{C}\right)$ \\
\hline Neat PLA blend film & 360 \\
PLA/Boltorn blend films & \\
95/5 & 366 \\
90/10 & 352 \\
80/20 & 334 \\
PLA/Boltorn-2CL blend films & \\
95/5 & 365 \\
90/10 & 358 \\
80/20 & 336 \\
PLA/Boltorn-4CL blend films & \\
95/5 & 367 \\
90/10 & 360 \\
80/20 & 358 \\
\hline
\end{tabular}


TGA analysis. From the TG thermograms, the initial decomposition temperatures $\left(T_{0} s\right)$ of the Boltorn ${ }^{\circledR}$ $\mathrm{H} 2004$ and the $\mathrm{CL}$ oligomers were approximate $300{ }^{\circ} \mathrm{C}$ and $250{ }^{\circ} \mathrm{C}$, respectively. This may be due to the $\mathrm{CL}$ chains reducing the intermolecular forces of the Boltorn ${ } \mathrm{H} 2004$ molecules. From the DTG thermograms, the hyperbranched Boltorn $® \mathrm{H} 2004$ showed two $\mathrm{T}_{\mathrm{d} \text { max }}$ values at $371{ }^{\circ} \mathrm{C}$ and $415^{\circ} \mathrm{C}$ that may be attributed to the decomposition of its outer and inner structures. The thermal stability changes of the $\mathrm{CL}$ oligomers can be clearly observed from the DTG thermograms. Both the $T_{d, \max }$ values of the Boltorn cores slightly decreased as the $C L$ units were added and increased. Then the thermal stability of the $\mathrm{CL}$ oligomers was a little lower than the Boltorn ${ }^{\circledR}$ $\mathrm{H} 2004$.

\section{Characterization of PLA blend films}

The film morphology was determined from SEM images. The film surfaces were smooth for

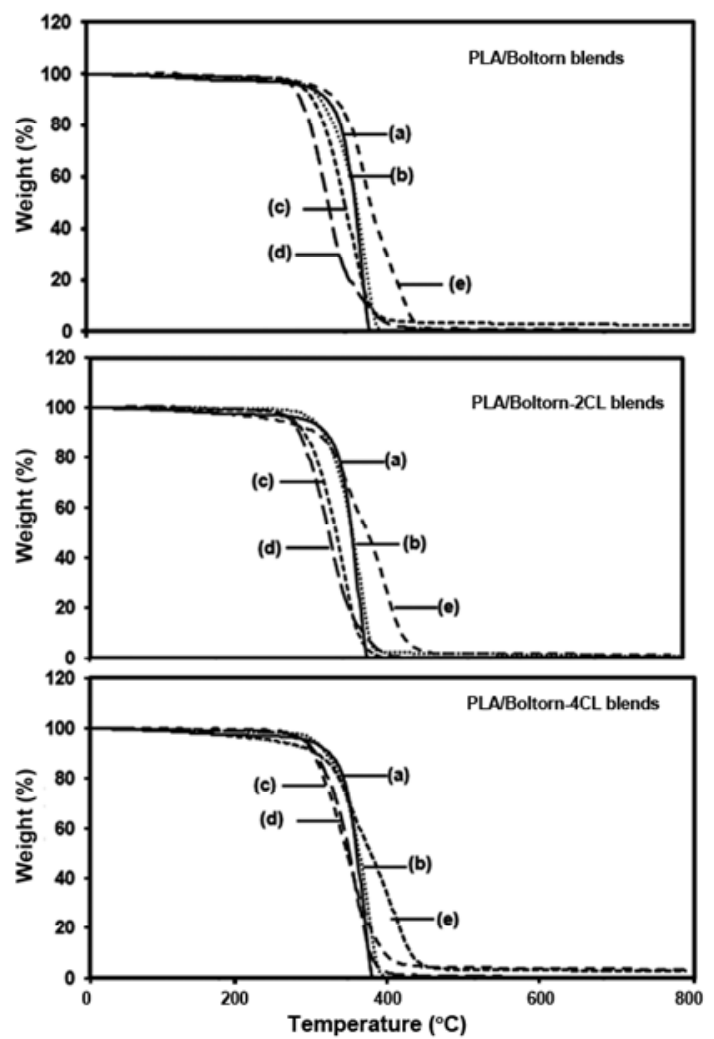

Fig. 5: TG thermograms of (a) neat PLA and PLA blend films prepared with PLA/plasticizer blend ratios of (b) $95 / 5$, (c) $90 / 10$ and (d) $80 / 20$ $(w / w)$ and (e) plasticizer. all the PLA blend films (SEM images not shown). Figures 4(a) - 4(d) illustrate the fractured surfaces of the neat PLA and the PLA/Boltorn $\otimes$ H2004 blend films. The fractured surface of the neat PLA film was continuous. Meanwhile, the PLA/Boltorn ${ }^{\circledR} \mathrm{H} 2004$ blend films revealed emptied voids on the fractured surfaces where the liquid Boltorn $\circledast \mathrm{H} 2004$ may have been accumulated during film drying similar to the PLA/PPG blend films. ${ }^{13,14}$ This suggests that phase separation between the continuous PLA and the dispersed Boltorn ${ }^{\circ} \mathrm{H} 2004$ phases had occurred. This may be due to the hydrophilicity of the six hydroxyl end-groups of the Boltorn ${ }^{\circledR}$ H2004that induced the phase separation. The void sizes increased significantly as the Boltorn $® \mathrm{H} 2004$ ratio increased [see Figures 4(b) - 4(d)]. Similar features were found on the fractured surfaces of the PLA/Boltorn$2 \mathrm{CL}$ and the PLA/Boltorn-4CL blend films. Emptied voids dispersed throughout the PLA/Boltorn-CL film matrices were also detected.

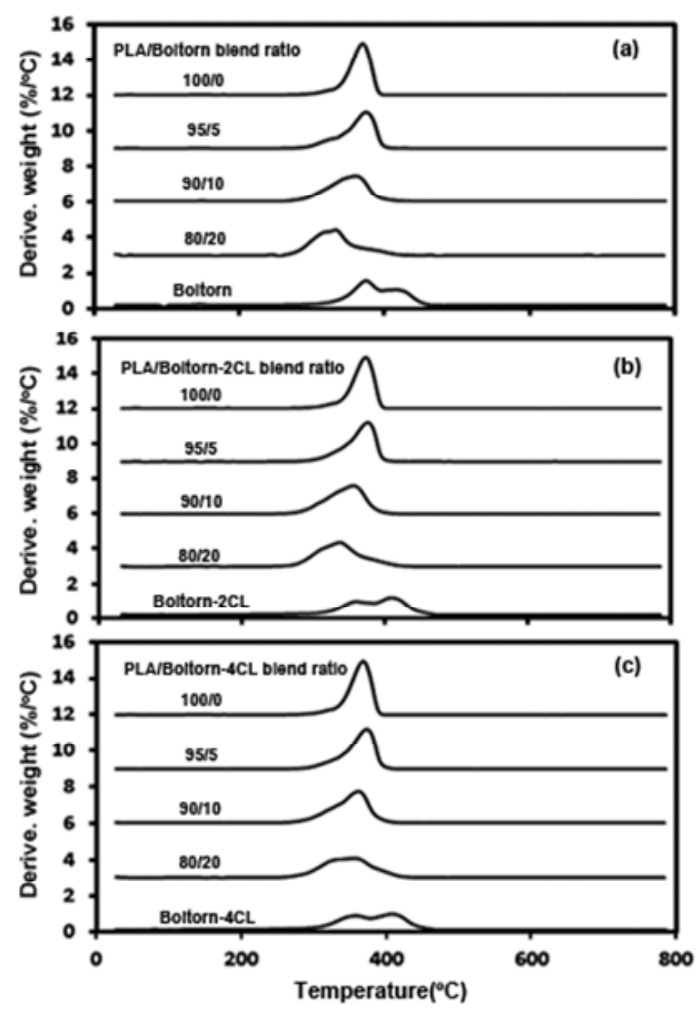

Fig. 6: DTG thermograms of (a) PLA/Boltorn, (b) PLA/Boltorn-2CL and (c) PLA/Boltorn$4 C L$ blend films preprared with different blend ratios. 
However, the void sizes of the PLA/BoltornCL blend films were smaller than those in the PLA/ Boltorn ${ } \mathrm{H} 2004$ blend films for the same blend ratio, and examples of these are shown in Figures 4(e) and 4(f) for the $20 \mathrm{wt} \%$ Boltorn-2CL and the $20 \mathrm{wt} \%$ Boltorn- $4 \mathrm{CL}$, respectively. This suggests that the hydrophobic $C L$ chains of the oligomers enhanced the phase compatibility by decreasing the hydrophilicity of the Boltorn ${ }^{\circledR} \mathrm{H} 2004$ cores.

The thermal transition properties of the PLA blend films were investigated from the $2^{\text {nd }}$ heating scan DSC thermograms, an example of which is shown in Figure 4 for the PLA/ Boltorn $®$ H2004 blend films. The $T_{g}, T_{c}$ and $T_{m}$ of the PLA phase were detected. The DSC results are summarized in Table 1, including the $X_{c}$ values. The $T_{g}, T_{c}$ and $T_{m}$ of the PLA blend films were a little lower than for the neat PLA film. This indicates that the Boltorn ${ }^{\circledR}$ $\mathrm{H} 2004$ and the Boltorn-CL acted as plasticizers to decrease the $T_{g}, T_{c}$ and $T_{m}$ of the PLA by enhancing the segmental mobility of the PLA in an amorphous phase. The $T_{g}$ slightly decreased as the plasticizer ratio increased.

The $X_{c}$ of the PLA are also summarized in Table 1, and they decreased slightly when the PLA was blended with the Boltorn $\circledast \mathrm{H} 2004$ and the blend ratio was increased. The $X_{c}$ of the PLA also decreased when the Boltorn-2CL and the Boltorn-4CL were blended for the $5 \mathrm{wt} \%$ blend ratio. However, the $X_{c}$ of the PLA increased as the Boltorn$\mathrm{CL}$ blend ratio increased from $5 \mathrm{wt} \%$ to 10 and 20 wt\%.This demonstrates that the Boltorn ${ }^{\circledR} \mathrm{H} 2004$ inhibited crystallization of the PLA, although the Boltorn' ${ }^{\circ} \mathrm{H} 2004$ and the Boltorn-CL had practically the same effect on the $T_{g}$. This result is similar to the plasticizing and nucleating effects on PLA films of poly(propylene glycol) (PPG) and poly(ethylene glycol) (PEG). ${ }^{13,14}$ The $T_{g}$ of the PLA films was depressed by blending with both the PPG and the PEG. However, the PPG affected the $X_{c}$ of the PLA less. In addition, the $T_{g}, T_{c}$ and $T_{m}$ of the PLA/Boltorn2CL and PLA/Boltorn-4CL blend films were similar for the same blend ratio. The $T_{g}, T_{c}$ and $T_{m}$ slightly decreased as the Boltorn-CL ratio increased. The results suggested that the number of $C L$ units did not affect on the thermal transition properties of the PLA in significant.

The thermal stabilities of the PLA blend films were determined from the TG thermograms, as shown in Figure 5. It can be seen that the thermal stabilities of all the plasticizers was better than those of the neat PLA and the PLA blend films. The neat PLA and the 95/5 wt\% PLA/plasticizer blend films showed similar single decomposition profiles in the temperature range of $300-400{ }^{\circ} \mathrm{C}$, with the initial

Table 3: Mechanical properties of PLA blend films

\begin{tabular}{lccc}
\hline $\begin{array}{l}\text { PLA/plasticizer blend } \\
\text { ratio (w/w) }\end{array}$ & $\begin{array}{c}\text { Stress at break } \\
\text { (MPa) }\end{array}$ & $\begin{array}{c}\text { Young's modulus } \\
\text { (MPa) }\end{array}$ & $\begin{array}{c}\text { Elongation at } \\
\text { break (\%) }\end{array}$ \\
\hline $\begin{array}{l}\text { Neat PLA film } \\
\text { PLA/Boltorn blend films }\end{array}$ & $3.8 \pm 0.2$ & $213.0 \pm 17.0$ & $5.4 \pm 0.8$ \\
$\quad$ 95/5 & $2.6 \pm 0.2$ & $158.6 \pm 20.9$ & $4.4 \pm 0.7$ \\
90/10 & $2.2 \pm 0.4$ & $147.6 \pm 17.0$ & $4.2 \pm 0.2$ \\
80/20 & $1.6 \pm 0.4$ & $87.6 \pm 8.8$ & $4.8 \pm 0.5$ \\
PLA/Boltorn-2CL blend films & & & \\
95/5 & $3.9 \pm 0.4$ & $193.5 \pm 24.6$ & $28.5 \pm 2.1$ \\
90/10 & $3.3 \pm 0.2$ & $167.2 \pm 27.9$ & $73.3 \pm 7.8$ \\
80/20 & $2.8 \pm 0.4$ & $155.1 \pm 38.6$ & $91.8 \pm 8.7$ \\
PLA/Boltorn-4CL blend films & & & \\
95/5 & $3.8 \pm 0.4$ & $204.5 \pm 10.7$ & $26.6 \pm 4.2$ \\
90/10 & $2.8 \pm 0.5$ & $182.8 \pm 27.8$ & $38.4 \pm 5.9$ \\
80/20 & $2.4 \pm 0.2$ & $148.8 \pm 13.1$ & $69.9 \pm 10.8$ \\
\hline
\end{tabular}


decomposition temperature about $300^{\circ} \mathrm{C}$. The weight losses of the $10 \mathrm{wt} \%$ and the $20 \mathrm{wt} \%$ plasticizer blend ratios were faster than the neat PLA film. The weight loss changes of the PLA films blended with Boltorn, Boltorn-2CL and Boltorn-4CL, were similar for the same blend ratios.

Figure 6 shows the DTG thermograms of the PLA blend films compared with their plasticizers. The PLA blend films exhibited single $T_{d, \text { max }}$ peaks. Table 2 reports the $T_{d, \max }$ of the PLA blend films. The $T_{d, \max }$ of the $95 / 5 \mathrm{wt} \%$ PLA/plasticizer blend films were higher than the neat PLA films for all the plasticizers. However, increasing the plasticizer ratios from $5 \%$ to $10 \%$ and $20 \%$ significantly depressed the $\mathrm{T}_{\mathrm{d}, \max }$.

The mechanical properties, including stress at break, elongation at break and initial Young's modulus, of the film samples were determined by tensile testing. Figure 7 shows the tensile properties

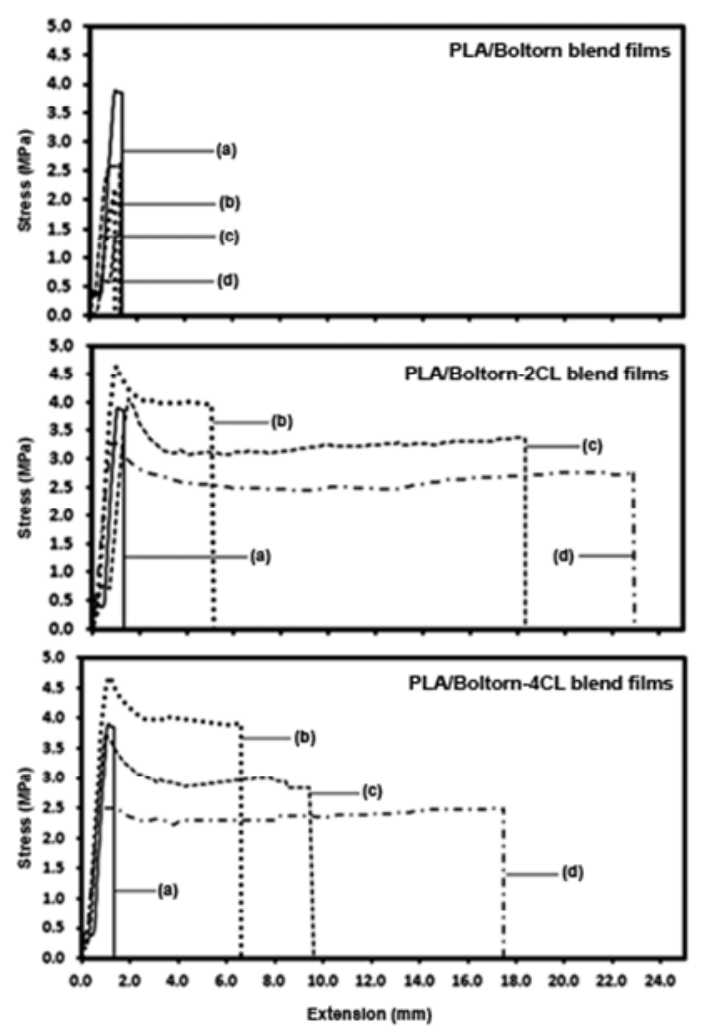

Fig. 7:Tensile curves of (a) neat PLA and PLA blend films prepared with PLA/plasticizer ratios of (b) 95/5, (c) 90/10 and (d) 80/20 wt\%. of the films as a function of the plasticizer type and the blend ratio. It can be seen that the elongation at break of the PLA films was not changed by the Boltorn ${ } \mathrm{H} 2004$ blending. While the Boltorn-2CL and the Boltorn-4CL blending can improve the elongation at break of the PLA films. In addition, the PLA/ Boltorn-2CL and the PLA/Boltorn-4CL blend films exhibited the yield or plasticizing effects for all the blend ratios, but the PLA/ Boltorn ${ }^{\circledR} \mathrm{H} 2004$ blend films did not. The results of the mechanical properties are summarized in Table 3. It was found that the stress at break and the initial Young's modulus decreased and the elongation at break increased as the Boltorn-2CL and the Boltorn- $4 \mathrm{CL}$ were blended and the blend ratio

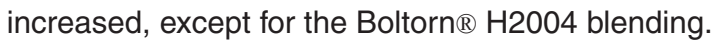
The results of the mechanical properties indicate that the Boltorn-2CL and the Boltorn-4CL improved the flexibility of the PLA films.

Kulinski et al., reported the plasticization of PLA films by tiny liquid pools of PPG during plastic flow, and this had positive effects on the film drawability. ${ }^{13}$ Thus, in this work, the tiny liquid pools of the Boltorn-CL enhanced the film drawability. The phase separation occurred on the PLA/Boltorn-CL blend films and induced a further slight decrease of the $T_{g}$ but largely enhanced the drawability of the PLA films, while the PLA/Boltorn ${ }^{\circledR} \mathrm{H} 2004$ blend films did not have this for all the blend ratios. This may be explained by the hydrophilicity between the continuous PLA and the dispersed Boltorn ${ }^{\circ} \mathrm{H} 2004$ phases being very different.

\section{CONCLUSIONS}

Two liquid Boltorn-CL oligomeric plasticizers were prepared by a ring-opening reaction of the $\mathrm{CL}$ monomer using the liquid star-shaped Boltorn $₫$ H2004 containing six hydroxyl end-groups as the initiator. The different $\mathrm{CL}$ units of oligomers (two and four units on each arm for the Boltorn-2CL and the Boltorn-4CL, respectively) were supported by ${ }^{1} \mathrm{H}-\mathrm{NMR}$ and TGA analyses.

The phase separation between the PLA and plasticizer phases can be clearly observed as the formation of emptied voids in the SEM images of their fractured surfaces. These emptied voids were the tiny pools of liquid plasticizer. The phase separation increased (sizes of tiny pools increased) 
with the plasticizer blend ratio. However, both the PLA/Boltorn-CL blend films showed less phase separation than the PLA/Boltorn ${ }^{\circledR} \mathrm{H} 2004$ blend film. The Boltorn ${ }_{\circledast} \mathrm{H} 2004$ and the Boltorn-CL blending slightly depressed the $\mathrm{T}_{\mathrm{g}}$ of the PLA. The tiny pools of the liquid Boltorn-CL oligomers obviously enhanced the plastic deformation to improve the drawability of the PLA films, but the liquid Boltorn ${ }^{\circledR} \mathrm{H} 2004$ did not. In conclusion, the flexibility of the PLA blend films can be tailored by controlling the Boltorn-CL blend ratio and the $C L$ chain length for potential use as flexible bioplastic films in packaging applications.

\section{ACKNOWLEDGEMENTS}

This work was supported by the Division of Research Facilitation and Dissemination, Mahasarakham University (2015). The Center of Excellence for Innovation in Chemistry $(\mathrm{PERCH}-$ $\mathrm{CIC}$ ), Office of the Higher Education Commission, Ministry of Education, Thailand is also acknowledged. The authors are very grateful to Dr. Jolyon Dodgson, Department of Biology, Faculty of Science, Mahasarakham University for hisimprovement of the English language in this manuscript.

\section{REFERENCES}

1. Garlotta D. A literature review of poly(lactic acid).J. Polym. Environ.2001,9, 63-84.

2. Lim, L. T.;Auras, R.; Rubino, M. Processing technologies for poly(lactic acid). Prog.Polym. Sci.2008, 33, 820-852.

3. Auras, R.; Harte, B.; Selke, S. An overview of polylactides as packaging materials. Macromol.Biosci.2003,4, 835-864.

4. Zhang, Z.; Chen, L. -B.; Gao, J.; Bao, F.; Yin, J.; Chen, B.;Wang, H.; Chen, Y.; Shang, L. Preparation of poly(sebacic anhydride) and polylactic acid pills used as drug carriers for levofloxacin controlled release. J. Polym. Eng.2013,33, 659-664.

5. Hassouna, F.; Raquez, J. -M.; Addiego, F.; Toniazzo, V.; Dubois, P.; Ruch, D. New development on plasticized poly(lactide): chemical grafting of citrate on PLA by reactive extrusion.Euro.Polym. J.2012,48, 404-415.

6. Choi, K.; Choi, M. -C.; Han, D. -H.; Park, T. -S.; Ha, C. S. Plasticization of poly(lactic acid) (PLA) through chemical grafting of poly(ethylene glycol) (PEG) via in situ reactive blending.Euro.Polym. J.2013,49, 23562364.

7. Liu, H,; Zhang, J. Research progress in toughening modification of poly(lactic acid).J. Polym. Sci. Part B: Polym. Phys.2011,49, 1051-1083.

8. Ljungberg, N.; Andersson, T.; Wesslen, B. Film extrusion and film weldability of poly(lactic acid) plasticized with triacetine and tributyl citrate. J. Appl. Polym. Sci.2003,88, 3239-
3247.

9. Maiza, M., Benaniba, M. T.; MassardierNageotte, V. Plasticizing effects of citrate esters on properties of poly(lactic acid).J. Polym. Eng.2015,36, 371-380.

10. Ljungberg N.; Wesslen, B. Tributyl citrate oligomers as plasticizers for poly(lactic acid): thermo-mechanical film properties and aging. Polymer2003,44, 7679-7688.

11. Hu, Y.; Hu, Y. S.; Topolkaraev, V.; Hiltner, A.; Baer, E. Crystallization and phase separation in blends of high stereoregular poly(lactide) with poly(ethylene glycol). Polymer 2003,44, 5681-5689.

12. Hu, Y.; Topolkaraev, V.; Hiltner, A.; Baer, E. Aging of poly(lactide)/poly(ethylene glycol) blends. Part 1.Poly(lactide) with low stereoregularity. Polymer 2003,44, 57015710.

13. Kulinski, Z.; Piorkowska, E.; Gadzinowska, K.; Stasiak, M. Plasticization of poly(Llactide) withpoly(propyleneglycol). Biomacromolecules 2006,7, 2 128-2135.

14. Piorkowska, E.; Kulinski, Z.; Galeski, A.; Masirek, R. Plasticization of semicrystalline poly(L-lactide) with poly(propylene glycol). Polymer 2006,47, 7178-7188.

15. Middle, J.C.; Tipton, A.J. Synthetic biodegradable polymers as orthopedic devices. Biomaterials 2000,21, 2335-2346.

16. Nair, L.S.; Laurencin, C.T. Biodegradable polymers as biomaterials. Prog.Polym. Sci.2007, 32, 762-798. 
17. Shi, G.; Cooper, D. G.; Maric, M. Poly(ecaprolactone)-based 'green' plasticizers for poly(vinyl chloride). Polym. Degrad. Stab.2011,96, 1639-1647.

18. Baimark, Y.; Srihanam, P. Influence of chain extension on thermal properties and melt flow index of stereocomplex PLA.Polym. Test.2015,45, 52-57.

19. Baimark, Y.; Cheerarot, O. Effect of chain extension on thermal stability behaviors of polylactide bioplastics. Orient. J. Chem.2015, 31, 635-641.

20. Pasee, S., Cheerarot, O., Baimark, Y.
Preparation of stereocomplex polylactide bioplastics from stae-shaped/linear polylactide blending. Orient. J. Chem.2015, 31, 15511558.

21. Niamsa, N.; Baimark, Y. Synthesis and characterization of poly (L-lactide-co-ecaprolactone)- $b$-poly(L-lactide) biodegradable diblock copolyesters: effect of block lengths on their thermal properties.J. Appl. Polym. Sci.2007, 106, 3315-3320.

22. Zhang, W.; Zheng, S. Synthesis and characterization of dendritic star poly(Llactide)s.Polym. Bull.2007,58, 767-775. 